\title{
Corrigendum: Endogenous fructose production and metabolism in the liver contributes to the development of metabolic syndrome
}

Miguel A. Lanaspa, Takuji Ishimoto, Nanxing Li, Christina Cicerchi, David J. Orlicky, Philip Ruzycki, Christopher Rivard, Shinichiro Inaba, Carlos A. Roncal-Jimenez, Elise S. Bales, Christine P. Diggle, Aruna Asipu, J. Mark Petrash, Tomoki Kosugi, Shoichi Maruyama, Laura G. Sanchez-Lozada, James L. McManaman, David T. Bonthron, Yuri Y. Sautin \& Richard J. Johnson

Nature Communications 4:2434 doi: 10.1038/ncomms3434 (2013); Published 10 Sep 2013; Updated 4 Dec 2013

The original version of this Article contained an error in the spelling of the author Philip Ruzycki, which was incorrectly given as Philip Ruzicky. This has now been corrected in both the PDF and HTML versions of the Article. 